\title{
Revistas Permutadas
}

\section{Títulos Nacionais}

1. Cadernos da Estef - Revista da Escola Superior de Teologia e Espiritualidade Franciscana / RIO GRANDE DO SUL

2. Caminhando com o Itepa - Instituto de Teologia e Pastoral / RIO GRANDE DO SUL

3. Coletânea - Revista de Filosofia e Teologia / RIO DE JANEIRO

4. Communio - Communio do Brasil / RIO DE JANEIRO

5. Convergência - Revista Mensal da Conferência dos Religiosos do Brasil CRB / RIO DE JANEIRO

6. Cultura e Fé - Instituto de Desenvolvimento Cultural / RIO GRANDE DO SUL

7. Diálogo: Revista de Ensino Religioso / RIO DE JANEIRO

8. Espaços - Revista de Teologia / SÃO PAULO

9. Estudos Teológicos - Escola Superior de Teologia / RIO GRANDE DO SUL

10. Fides Reformata - Igreja Presbiteriana do Brasil / SÃO PAULO

11. Filosofazer - Revista do Instituto Superior de Filosofia Berthier RIO GRANDE DO SUL

12. Horizonte - Revista de Estudos de Teologia e Ciências da Religião MINAS GERAIS

13. Horizonte Teológico - Instituto Santo Tomás de Aquino / MINAS GERAIS

14. In Certezas - Revista do Programa de Pós-Graduação em Ciências SÃO PAULO 
15. Interações Cultura e Comunidade - Revista de Ciências da Religião MINAS GERAIS

16. Itaici - Revista de Espiritualidade Inaciana / SÃO PAULO

17. Kairós - Revista Acadêmica da Prainha / CEARÁ

18. Mundo e Missão - Revista do Pontifício Instituto das Missões - PIME SÃO PAULO

19. Numen - Universidade de Juiz de Fora / MINAS GERAIS

20. Perspectiva Teológica - Faculdade Jesuíta de Filosofia e Teologia MINAS GERAIS

21. Razão e Fé - Revista - Inter e Transdisciplinar de Teologia, Filosofia e Bioética / RIO GRANDE DO SUL

22. REB - Revista Eclesiastica Brasileira / RIO DE JANEIRO

23. Redes, Revista Capixaba de Filosofia e Teologia / ESPÍRITO SANTO

24. Reflexão - Revista Semestral da Faculdade de Filosofia / SÃO PAULO

25. Reflexus - Revista Semestral de Estudos Teológicos / VITÓRIA

26. Remhu - Revista Interdisciplinar da Mobilidade Humana / BRASÍLIA

27. Revista Brasileira de Direito Canônico - Direito e Pastoral / RIO DE JANEIRO

28. Revista de Cultura Teológica - Centro Universitário Assunção / SÃO PAULO

29. Revista Pisatis \& Praxis: Teologia e Pastoral / PARANÁ

30. Revista Sistemática Equatorial - Revista da Faculdade Teológica Batista Equatorial / PARÁ

31. Revista Trilhas - Revista Teológica Pastoral - FAMIPAR / PARANÁ

32. Rhema - Revista de Filosofia e Teologia do Instituto Teológico Arquidiocesano Santo Antônio / MINAS GERAIS

33. Teocomunicação - Revista da Faculdade de Teologia da PUC-RS RIO GRANDE DO SUL

34. Theophilos - Revista de Teologia e Filosofia - Universidade Luterana do Brasil / RIO GRANDE DO SUL

35. TQ - Teologia em Questão / SÃO PAULO

36. Veritas - Edipucs / RIO GRANDE DO SUL

37. Via Teológica - Faculdade Teológica Batista do Paraná / PARANÁ

38. Vox Scriptura - São Bento do Sul / SANTA CATARINA

39. Voz Amiga - Congregação de Jesus Sacerdote / São PAULO 


\section{Títulos Estrangeiros:}

1. Alpha Omega - Rivista di Filosofia e Teologia dell'Ateneo Pontifício Regina Apostolorum / ITÁLIA

2. Analecta Cracoviensia - Revista da Pontifícia Academia Theologica Cracoviensis / POLÔNIA

3. Anales de Teologia - Universidad Católica de la Santíssima Concepción CHILE

4. Andrews University Seminary Studies / USA

5. Cuadernos - El Derecho de Acceso a La Vivienda / ESPANHA

6. Cuadernos de Teologia - Instituto Universitário - ISEDET / ARGENTINA

7. Cuestiones Teológicas y Filosóficas - Universidade Pontificia Bolivariana COLÔMBIA

8. Didaskalia - Revista da Faculdade de Teologia / LISBOA

9. Ecclesia - Rivista de Cultura Catolica / ROMA

10. Estúdios Sociales / REPÚBLICA DOMINICANA

11. Família et Vita - Pontificio Consiglio per la Famiglia / ITÁLIA

12. Folia Theologica / HUNGRIA

13. Franciscanum - Revista de las Ciências del Espiritu / COLÔMBIA

14. Instituto Paolo VI. Notiziario / ITÁLIA

15. Isidorianum - Centro de Estudos Teologicos de Sevilla / ESPANHA

16. Iter - Instituto de Teologia para Religiosos / VENEZUELA

17. Laos - Rivista di Science Religiose e Humanistiche / ITÁLIA

18. Medellín - Teologia y Pastoral para América Latina / COLÔMBIA

19. Mission - Revista de la Compañía de Jesús en Uruguay / URUGUAI

20. Nigrizia - Revista Mensile Dei Missionari Colombiani / ITÁLIA

21. Notiziario - Consejo Pontificio para los Laicos / ITÁLIA

22. Notiziário della rete Radié Resch / ITÁLIA

23. Páginas - Revista Acadêmica e Institucional de la UCPR / COLÔMBIA

24. Philosophy, Culture e Traditions / CANADÁ

25. Proyeccion - Facultad de Teologia / ESPANHA

26. Revista Iberoamericana de Teologia / MÉXICO

27. Revista Latinoamericana de Teologia / EL SALVADOR

28. Revista de Teología / REPÚBLICA ARGENTINA

29. Revue de L'Université Catholique de Lyon / FRANÇA

30. Rucao - Revue de L'Université Catholique de L'Afrique de L'Quest ÁFRICA

31. Selecciones de Teología - Facultad de Teología de Catalunya / BARCELONA

32. Seminarium - Libreria Editrice Vaticana / ITÁLIA

33. Spiritualità Monfortana-International de Monfortain / COLOMBIA

34. Spiritus - Revista de Missionologia, Edición Hispanoamericana / EQUADOR 
35. Stromata - Revista de Filosofia y Teologia / ARGENTINA

36. Studi Ecumenici - Revista del Istituto di Studi Ecumenici S. Bernardino VENEZA

37. Studia Patavina - Rivista di Scienze Religiose / ITÁLIA

38. Studium Filosofia y Teologia - Universidad del Norte Santo Tomás de Aquino / ARGENTINA

39. Teologia - Revista della Facoltà Teológica dell'Italia Settentrionale ITÁLIA

40. Teologia y Vida - Facultad de Teología / CHILE

41. Theologia Xaveriana - Estudios Sociales de la Religión / COLÔMBIA

42. The Princeton Seminary Bulletin / USA

43. Transversalités - Revue de L'Institut Catholique / PARIS

44. Vita e Pensiero - Università Cattolica del Sacro Cuore / ITÁLIA

45. Voces - Revista de Teologia Missionera del Instituto Internacional de Filosofia A.C / MÉXICO

46. Voices From The Third World / ÍNDIA 